\title{
The wedge effect in the beam column joint of the Multipurpose Construction System for Cuba (SMAC system)
}

\author{
El efecto cuña en la unión viga-columna del sistema de Múltiple Aplicación para Cuba (SMAC)
}

\section{Leonardo Ruiz Alejo (Main Author)}

Instituto Superior Politécnico José A. Echeverría, Ingeniería Civil, Estructuras.

Calle 114 No. 11901 entre Ciclovía y Rotonda, Marianao, La Habana, Cuba

\begin{abstract}
In the present paper an innovative solution for a structurally continuous beam- column joint in prefabricated structure is described. It is rapidly executed and very safe and has been widely used in different constructions for research centers, universities and others. This type of connection is one of the distinguished features in the Multipurpose Construction System for Cuba (SMAC System).

Its behavior is based on the wedge effect and friction action developed between two inclined planes in both elements being connected. Ful scale tests are described herein and the results obtained proved the efficiency. Transmission of vertical loads as well as bending moments through the joint are guaranteed. This is particularly important in frame structures since horizontal loads due to wind are very large in Cuba because of hurricanes.
\end{abstract}

Keywords: Precast system; Beam-column joint; Wedge effect; full scale test, SMAC system.

\section{Introduction}

The precast technique meant a revolution in the development of societies because of the advantages derived in the construction of buildings and bridges. Great panel constructions allowed the erection of dwelling houses and other types of buildings in a massive way in which the reduction of time was an important factor.

At the same time, the repetitive production of equal or similar components permitted that molds were used many times obtaining a high quality in the finishing of them. Many structural engineers think that a serious limitation of precast construction results from the difficulties in getting an effectively continuous joint between precast elements that be simple to be executed.

The benefits of monolitism in the traditional in situ construction can't be obtained in prefabrication, especially in the achievement of continuity in beam column joints. Solutions based in the use of welding, bolts or screws as they do in metal structures and protruding bars projecting from the elements to be connected, as well as the prestressing technique, basically in high risk seismic zones to dissipate energy have been widely employed (Maspons, 1987; Negro \& Toniolo, 2012).

Several of this methods for connecting the precast elements follow the objective to emulate monolithic construction to achieve satisfactory performances (Alcocer et al., 2002; Im et al., 2013).

\author{
Janet Otmara Martínez Cid (Contact Author) \\ Instituto Superior Politécnico José A. Echeverría, Cuba \\ Calle 114 No. 11901 entre Ciclovía y Rotonda, Marianao, La Habana, \\ Cuba \\ jcid@civil.cujae.edu.cu
}

\author{
Manuscript Code: 511 \\ Date of Reception/Acceptance: 01-010-2014 / 01-12-2015.
}

\begin{abstract}
Resumen
En el presente trabajo se describe una novedosa solución para una unión continua viga columna en estructuras prefabricadas. La misma es segura y de rápida ejecución y ha sido ampliamente empleada en diferentes construcciones para centros de investigación, universidades y otras obras. Este tipo de conexión constituye uno de los aspectos significativos en el Sistema de Múltiple Aplicación para Cuba (SMAC).

Su comportamiento se basa en la fricción desarrollada gracias al efecto cuña entre dos planos inclinados pertenecientes a los elementos que se conectan. Se describen ensayos a escala natural y los resultados que se obtuvieron confirmaron la eficacia de la unión garantizándose la trasmisión de cargas verticales y de momentos flectores. Esto es particularmente importante en estructuras porticadas en Cuba ya que las cargas horizontales provocadas por el viento son muy altas a causa de los huracanes.
\end{abstract}

Palabras Claves: Sistema prefabricado, unión viga-columna, efecto cuña, Sistema SMAC, ensayos uniones.

It is justified to design structures with as many redundant ties as possible; this means a major factor of safety not only in the case that act usual loads but also when uncommon loads such as vehicles' impact and accidental or provoked explosions are present. It is also a positive fact the existence of redundant ties if loads are larger than those considered in the design.

In the case of seismic loads, it is very important that structures have a great reserve of resistance and ductility and it is known that isostatic structures lack of them. In some regions of Cuba, seismic loads have to be included in the design, while wind loads due to hurricane must be included in the whole country. That makes statically indeterminate frames more economical and structurally efficient than isostatic frames.

Several factors have encouraged international research in the field of precast continuous beam column joint (Alcocer, Carranza, \& Perez-Navarrete, 2000; Alcocer et al., 2002; Cheok \& Lew, 1991; Im et al., 2013; Kusuhara, Asukawa, Shiohara, \& Otani, 2004; Shariatmadar \& Zamani, 2011). The following can be quoted among the most relevant: the difficulties in the obtainance of a simple beam column joint, its uncertain behaviour when loads act and the increasing concern in the aspect of the safety of structures.

\section{Description of the problem}

During the decade of the '50s of the last century in Cuba, the precast industry was limited to the construction of electric posts and small prestressing purlins for floors and roofs. A very simple system called Novoa was also developed for one floor individual dwelling houses. From the decades of the '60s 
on, the prefabrication industry was widely extended to face a great necessity of schools, houses, agricultural complexes, industries and other installations. In the middle of the '70s, a prefabricated system was developed consisting of four basic types of elements: the main beam, the edge beam, the slab and the column; it was called SMAC, Multipurpose Construction System for Cuba.

The main objective of the work was to obtain a prefabricated construction system whose behaviour under load were similar to one casted in situ and that were easily executed. It was intended to be applicated to social buildings up to 18 stories high, with beam's and slab's spans between 8600 and 18000 $\mathrm{mm}$ and being capable of supporting overloads until $15 \mathrm{kN} / \mathrm{m} 2$.

This precast system was distinguished by a new concept in the solution of the beam column joint. Continuity between these elements was achieved by the effect of friction, instead of using metal or concrete brackets, welding, bolts or screws or protruding bars from the components to be connected. The effectiveness of this solution were validated by actual SMAC buildings, some of which were built over 20 years ago.

In order to apply the wedge effect concept to other architectural programs like housing buildings, in which the requirements on values of spans, intercolumns and loads are smaller than required to social building, it is necessary to expand the knowledge of the behavior of this continuous beam column joint solution.

In the present paper, the fundamental characteristics of the beam column joint in the SMAC system are related as well as the experimental research made considering the action of symmetric and nonsymmetrical loads on the beam. The results of the experiments are exposed for a better explanation and a further application of its advantages to other cases.

\section{Multipurpose Construction System for Cuba} (SMAC system)

The SMAC system was developed in the decade of the '70s of the last century in Cuba (Tosca \& Ruiz, 1989). The system is composed by frames with reinforced concrete columns of rectangular $300 \times 600$ and $300 \times 900 \mathrm{~mm}$ transverse sections. These columns are several stories high in one unit. Beams are reinforced or prestressed concrete and consist of two longitudinal ribs and transverse ribs spaced $1200 \mathrm{~mm}$. Eventually, longitudinal edge beams might be needed to support facade elements. On the other hand, double and simple $\mathrm{T}$ prestressed concrete slabs as well as prestressed hollow slabs are employed for floors and roofs.

\section{Joint description}

A new conception has guided the design of the beam column joint. This connection is characterized by the spacial intersection of the beam and the column and the pouring of concrete in the space left between both elements (Figure 1).

To do this, the beam must be lifted until the top of the column and then descended to the level under consideration. For this operation holes have been left on the superior part of the beam during its construction. Temporary metal brackets are situated on the proper level and fixed to the column by means of a steel massive cylinder $100 \mathrm{~mm}$ diameter.

The brackets have leveling screws which serve to correct the dimensional differences generated during fabrication and erection. Thanks to this, a perfect horizontality of the beam is achieved as has been proved in the existing buildings. Once the specified compressive resistance of concrete is obtained, the temporary support is removed to be used in other parts of the building.

Shear forces and bending moments are transmitted through the cast in situ concrete due to the friction effect in the wedge type connection created. A system of slots existing in the faces of the beam and the column and the couple of forces generated between the short faces of the column and the transverse ribs of the beam contribute to resist the bending moment in the joint.

The wedges are formed between the inclined planes in the interior faces of the longitudinal ribs of the beam and the depressions in the longest sides of the column section (Figure 2). The vertical slots left in the inclined planes in the beam and the column greatly contribute to resist the bending moments in the joint and also increase the force of friction generated in these planes.

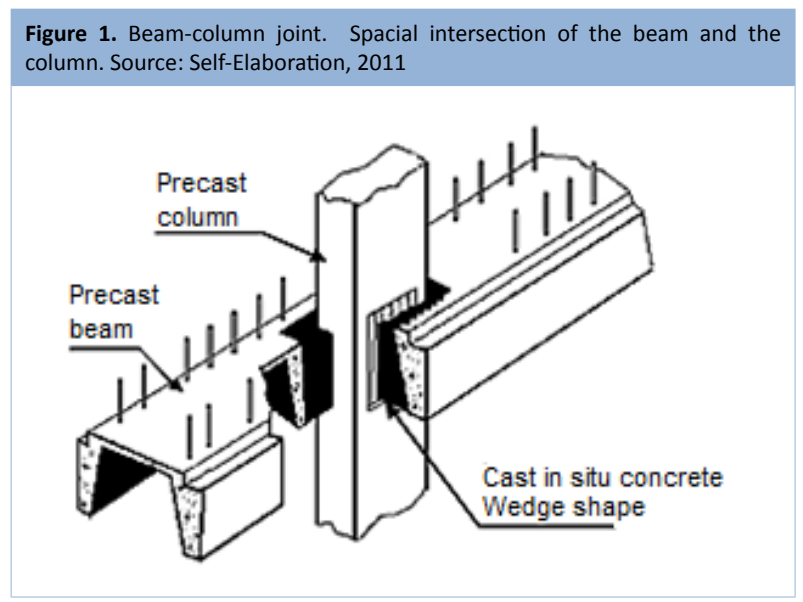

Once the $2 \mathrm{~T}$ or the hollow slabs which constitute the floors are placed in position, a $120 \mathrm{~mm}$ thick layer of concrete is poured over the beam all the way long; it serves for positioning the negative reinforcement and at the same time allows the floor to participate in the lateral load resistance of the structure.

When concrete in the connection has hardened, the inclined planes and the slots guarantee the development of friction, which in turn, opposes shear forces. Furthermore, when vertical loads from the upper floors act on the joint, the confinement effect in the concrete produces an increase in its compressive strength and consequently a reduction in the strains due to the restriction in its lateral displacement. As a result, an increase in concrete strength is obtained as compared with its specified strength.

The formwork for concreting the joint consists of a simple board placed over the temporary metal support and both the joint and the support for the beam were designed in such a way that two complete levels of prefabricated slabs could be mounted before casting the beam column joints and the strips over the beams.

This permits that the two actions could take place at the same time allowing an interrupted sequence in the mounting of prefabricated elements without any risk for structural stability during erection (Tosca \& Ruiz, 1989). The beam column connection in the SMAC system, being structurally continuous, is very efficient in resisting lateral wind and seismic loads with no need of rigid vertical walls or any other type of bracing. As a 
result, the cost of foundation and superstructure diminishes as compared with hinged beams frame structures.
The advantages derived from the beam column joint in the SMAC system (Figure 3) as well as its innovative characteristics, determined that it were patented in Cuba, The United Kingdom, Germany, Czech Slovakia and The Soviet Union.

Figure 2. Geometry of precast elements. Details of the inclined planes and the slots. Source: Self-Elaboration, 2013
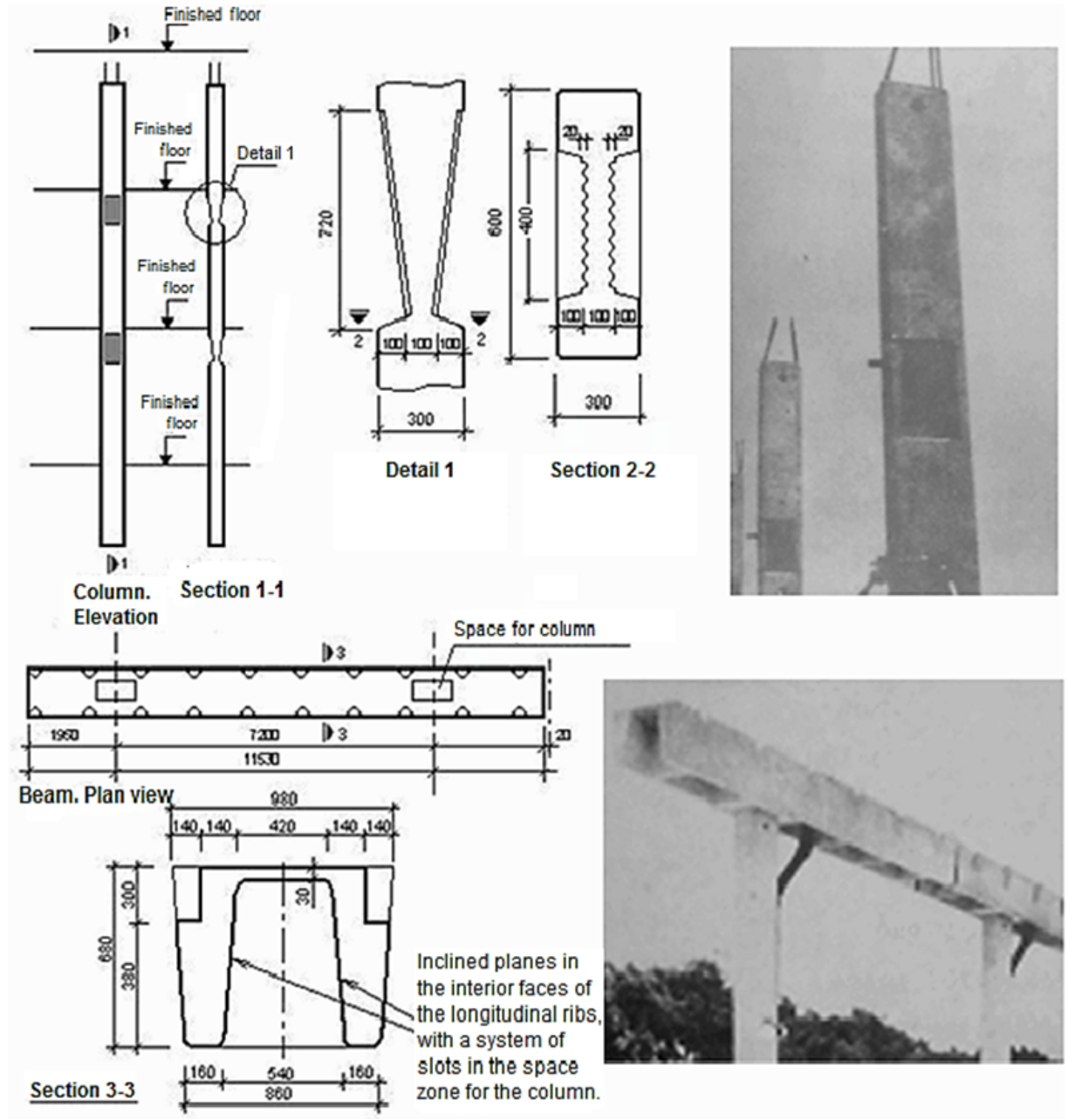

Figure 3. Geometry and reinforcement details of the beam-column joint. Source: Self-Elaboration, 2013

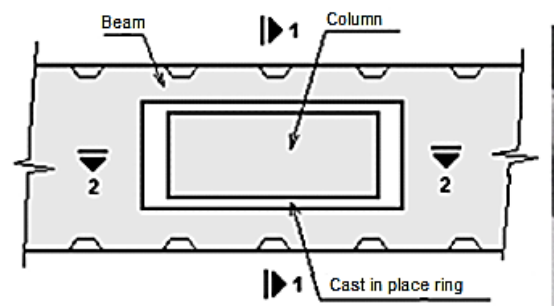

Beam-column joint. Plan view
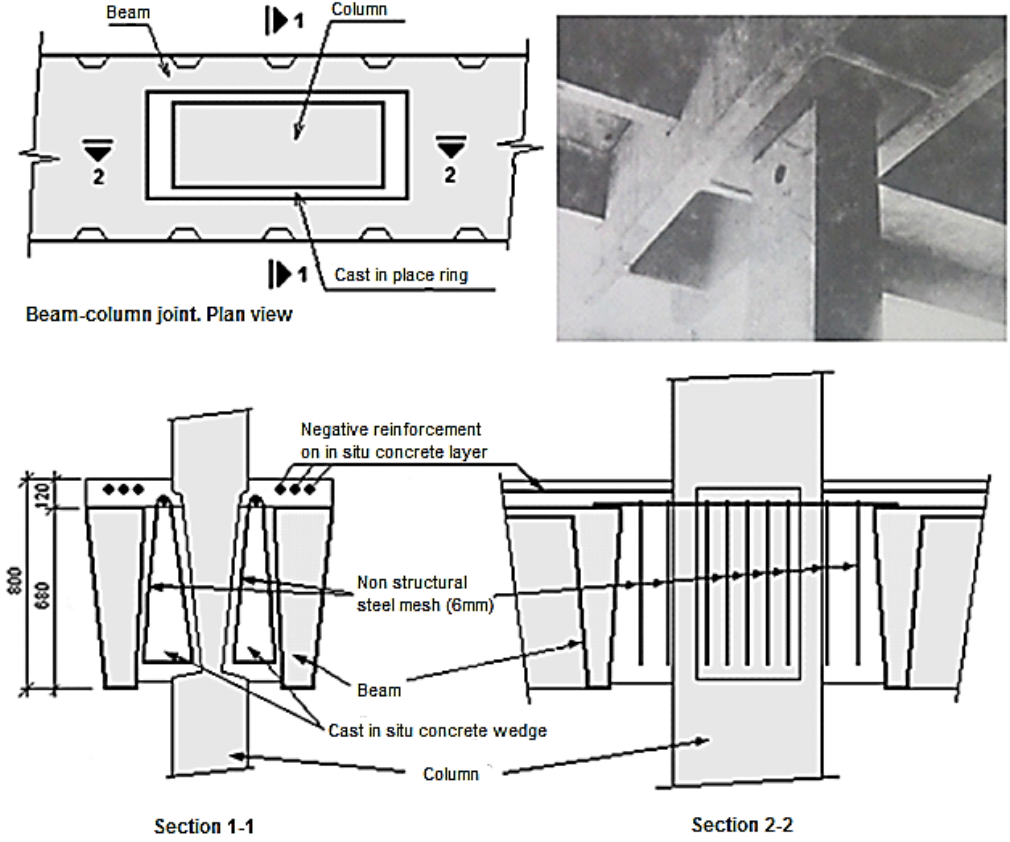


\section{Description of the tests}

The research took place from June 1987 to December 1988 in the Technical Center for the Development of Construction Materials in Cuba. Through this work it was intended to study and comprehend the behaviour of the connection under the action of symmetric and nonsymmetrical loads and evaluate the vertical load capacity in the first case and the vertical load and bending moment capacity in the second case (Paredes, Ruiz, \& Tosca, 1988).

Full scale tests were made on an intermediate beam column joint of an ideal multistory building; therefore, a vertical load on the column generated by a hydraulic jack was included simulating the action of the uppermost levels. The column was embedded on its base and a beam $3600 \mathrm{~mm}$ long symmetrically placed was used in the test $(1800 \mathrm{~mm}$ on each side of the column). Elements were designed according to the existing code at the time NC -53-039: 1978.

\section{Symmetrical loads test}

Three concentrated loads were simultaneously applied: an axial load P on top of the column and two concentrated loads P1 and $\mathrm{P} 2$ on the beam (one on each side of the column). The constant load $\mathrm{P}=900 \mathrm{kN}$ represents the weight due to several floors: this load shortens the column vertically and expands it in the transverse direction, increasing the concrete confinement in the joint. It supposes a friction rise in the interphase between the concrete wedge and the column. Eleven loads increments between 56 and $172 \mathrm{kN}$ were added until P1 and P2 reached the maximum value of $1176 \mathrm{kN}$.

Average concrete compressive strength for the cast in situ concrete was $20 \mathrm{MPa}$ while a $6 \mathrm{~mm} \mathrm{G}-34$ (fy=240 MPa) steel mesh was added in the free space in the joint between precast elements. Ten strain gages were located in different points of the beam and the column to determine the displacements resulting from the application of the loads.

Strain gages 1 and 5, 2 and 6 and 3 and 7 were placed in homologous points in opposite sides of the concrete wedge and under the longitudinal ribs in the beam; in this way, the vertical deformations of the joint under loads were reported during the test. Strain gages 4 and 8 were located on opposite sides of the column to evaluate its shortening and strain gages 9 and 10 served to determine the vertical displacements at the ends of the beam (Figure 4). Figures 5 and 6 show the values of displacements in the strain gages (negative values indicate downward movements).

According to the graphs in Figures 5 and 6 it can be concluded: 1. Values observed in strain gage 6 are not reliable since the corresponding information was lost for load values P1 and P2 greater than $947 \mathrm{kN}$.

2. There are small differences in the readings of displacements between strain gages 1 and 5, 3 and 7 and 4 and 8 which is probably due to natural lack of precision in lab tests such as inexact location of hydraulic jacks, the differences in the physical properties of concrete in various zones and human errors during the procedure.

3. In conformity with the two previous points 1 and 2 , values reported on strain gage 2 were accepted as valid.

4. Average values of displacements measured in strain gages 4 and 8 in the column and strain gage 2 in the beam proved that relative displacement between the beam and the column was lower than $2 \mathrm{~mm}$ under ultimate loads.

5. No failure of the beam column joint was detected even when the axial load on the column was $\mathrm{P}=900 \mathrm{kN}$ and $2352 \mathrm{kN}$ due to the total load applied at the ends of the beams, whereas the bending moment was $2117 \mathrm{kNm}$.

6. The ultimate resistance of the beam was reached before failure of the joint occurred (Figure 7).

Figure 4. Details of experiment setup. Source: Self-Elaboration, 2012

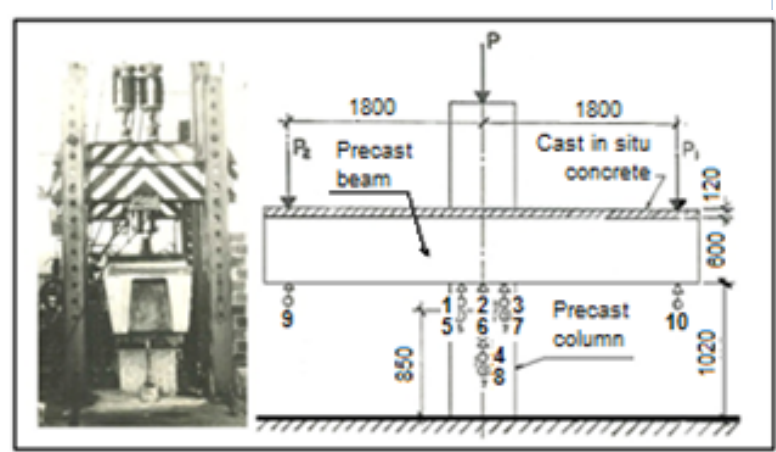

Figure 5. Displacements of strain gages points for each load increment. Source: Self-Elaboration, 2013.

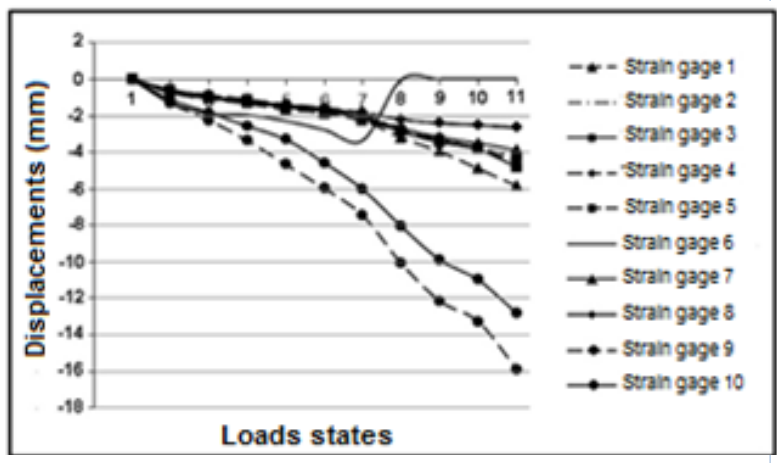

Figure 6. Displacements of strain gages points along the beam for ultimate load (P1=P2=1176 kN). Source: Self-Elaboration, 2013

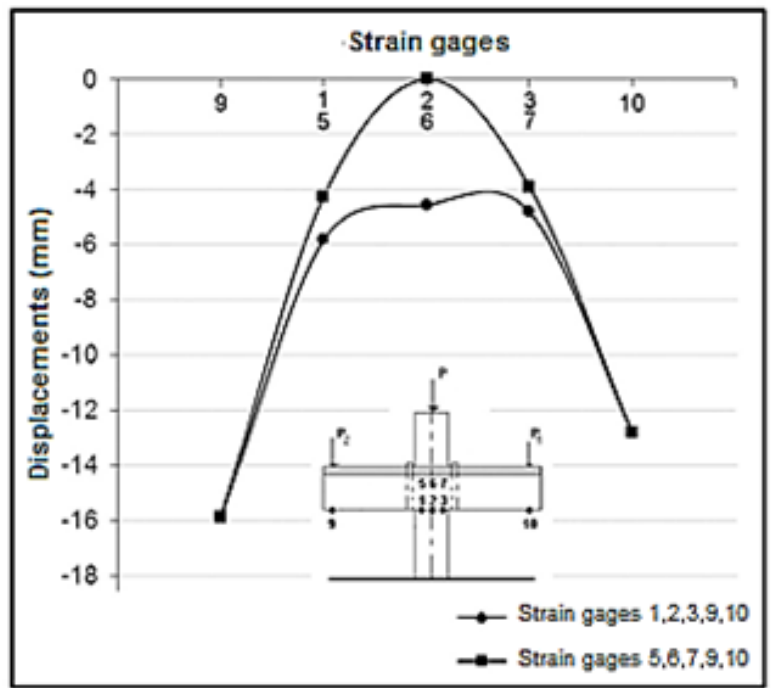




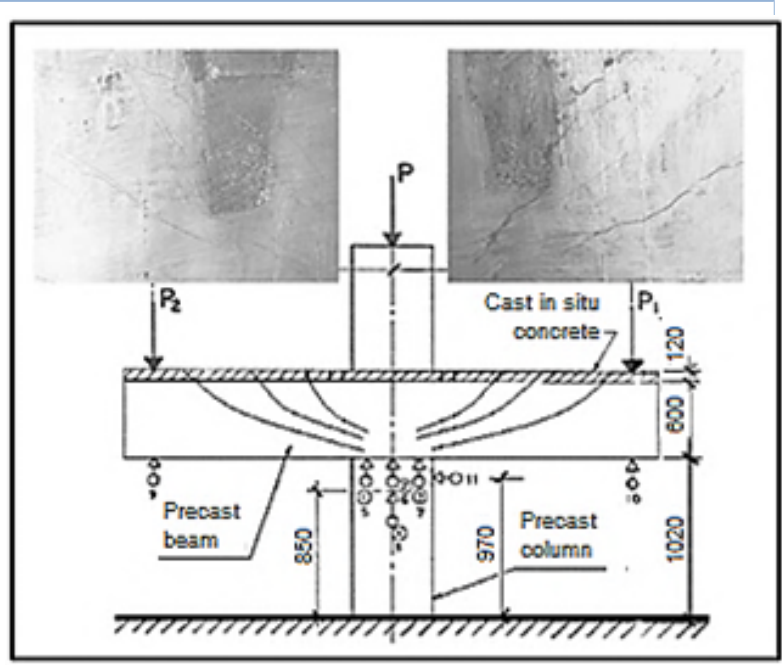

\section{Unsymmetrical loads test}

This test was carried out generating a bending moment due to increasing values of load $P 1$ while load $P 2=0$. Cast iron pipes were left into the concrete, one on each side of the column to simulate rainwater downpipes. A constant $400 \mathrm{kN}$ axial load was applied on top of the column and $50 \mathrm{kN}$ increments were applied to generate P1. In figures 8 and 9 values of displacements read in the strain gages are related (negative values indicate downward movements).

After checking the results it can be pointed out:

1. Bending moments act on the joint due to the different values of loads P1 and P2; it must be resisted exclusively by the inferior part of the column. The angular displacement of the column relative to the built in end is determined through the readings in strain gage 11 .

2. Relative rigidity of the beam respect to the column's rigidity is so high that it rotates like a rigid body relative to the joint. This can be verified when one compares the values of displacements in strain gages 9 and 10 which are similar but with opposite signs (Figures 8 and 9).

3 . The variation in sign in the readings of strain gages 1,2 and 3 , as well as in strain gages 5, 6 and 7 confirm what was expressed in point 2 .

4. It must be remarked that for values of P1 greater than 350 $\mathrm{kN}$, a reaction shows up in $\mathrm{P} 2$ which proves that rotation of the joint commences to be restricted and bending moment due to load P1 is resisted, not only by the column, but also by the part of the beam where load P2 acts.

5. The greatest difference between load values P1 - P2 is obtained when $\mathrm{P} 1=900 \mathrm{kN}$ and $\mathrm{P} 2=429 \mathrm{kN}$; therefore, the maximum bending moment applied to the joint was $M=847,8$ $\mathrm{kN}-\mathrm{m}$.

6. At this moment, the load transferred from the column to the joint was $400 \mathrm{kN}$ and from the beam was transferred $1329 \mathrm{kN}$.
Figure 8. Displacements of strain gages points for each load increment. Source: Self-Elaboration, 2013

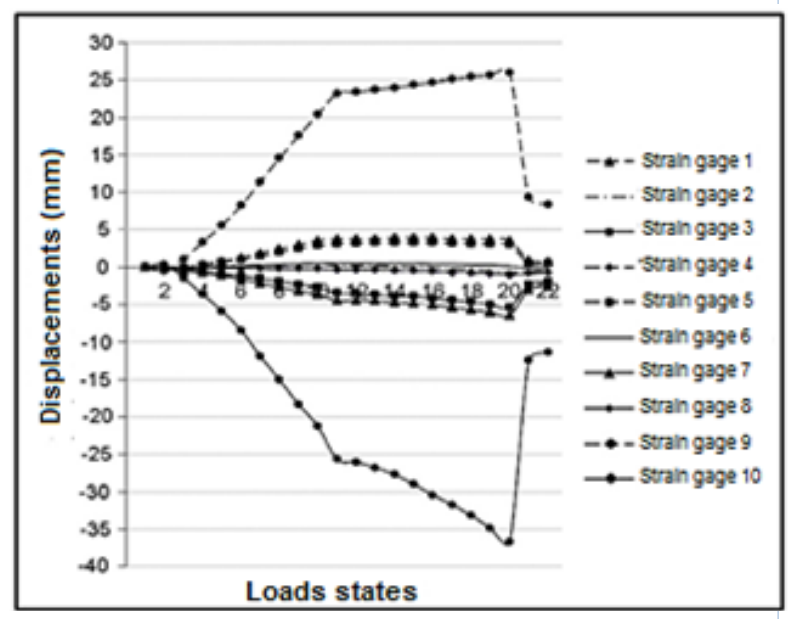

Figure 9. Displacements of strain gages points along the beam for ultimate loads (P1=900 kN, P2=429 kN). Source: Self-Elaboration, 2013

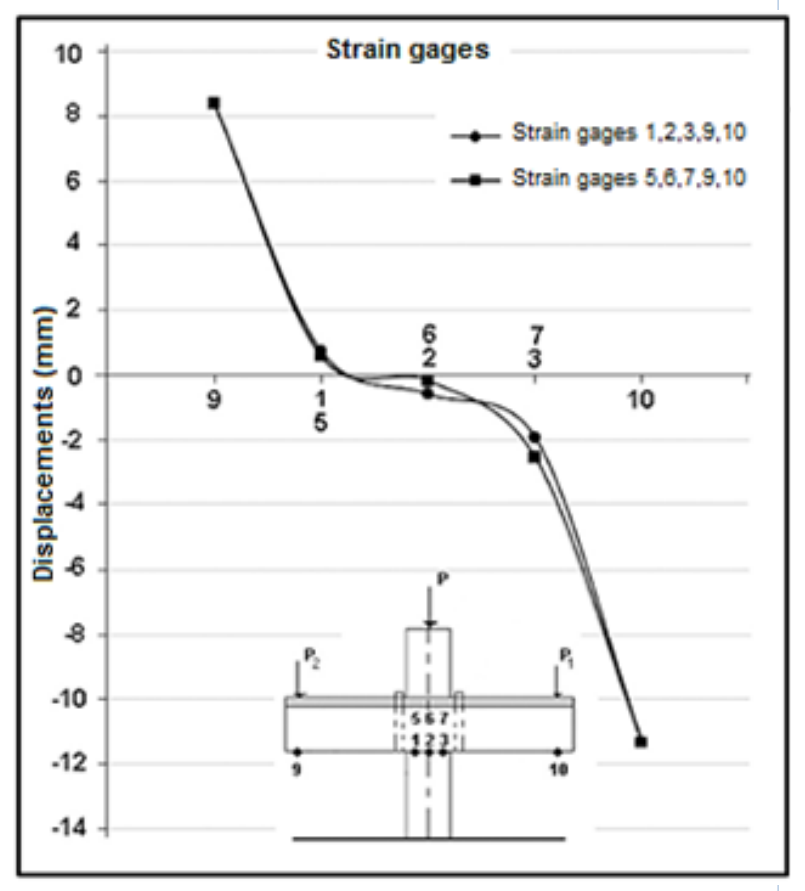

\section{Conclusions}

Based on the test results, the following conclusions are drawn: 1. The behaviour under load of the SMAC's beam column joint is excellent since loads applied during the tests are much larger than those actually expected on the structure. At the same time, it was verified that no relative displacements occurred between both elements, nor deterioration of concrete in the wedge took place.

2. The bending moment transmitted to the joint by the beam provoked its failure without breaking the connection.

3. Since beam's rigidity is much larger than column's rigidity, rotation of the joint is determined by column's capability of preventing it.

4. Steel reinforcement in the concrete wedge must be limited to a $6 \mathrm{~mm}$ diameter mesh, with bars spaced 250 to $300 \mathrm{~mm}$ in both directions around the column.

5. The minimum specified concrete compression strength in the joint must be $f^{\prime} c=20 \mathrm{MPa}$.

6. Vertical loads over $2500 \mathrm{kN}$ are transmitted by flexure of the 
beams while a $900 \mathrm{kN}-\mathrm{m}$ bending moment value is resisted by the joint.

7. The concrete wedge generated in the beam column joint guarantees the structural continuity of the union and furnishes several construction advantages, all of which constitute an inspiration for new applications of the system.

Test results were corroborated by actual SMAC buildings, some of which were built over 20 years ago. Among them, the Agrarian University of Havana (1978), the Genetic Engineering and Biotechnological Center (1986), the Pharmacy Chemistry Center (1990) and the Hotel Montehabana (1995) have had an excellent performance even in the case of the action of extreme horizontal wind loads.

\section{Future researches}

A mathematical computational model of the beam column connection which includes the wedge effect based upon test results is being elaborated to calibrate the model mathematically and physically. Once this model be validated, the main purpose of the present work is to strengthen the knowledge of the beam column joint behaviour in order to apply the wedge effect concept to other architectural programs in which the requirements on values of spans, intercolumns and loads are smaller than those planned during the original design of the SMAC system.

\section{Acknowledgement}

The authors want to thank architect Juan A. Tosca Sotolongo for his valuable contributions to the development of structural engineering in Cuba. We also thank the Technical Center for the Development of Construction Materials for its cooperation. Thanks also to Dr. Eng. Ricardo Fernández Álvarez for its precise comments.

Alcocer, S., Carranza, R., \& Perez-Navarrete, D. (2000). Behaviour of a precast concrete beam-column connection . 12th World Conference on Earthquake Engineering.

Alcocer, S., Carranza, R., Perez-Navarrete, D., \& Martinez, R. (2002). Seismic Tests of Beam-to-Column Connections in a Precast Concrete Frame. PCI Journal, 70-89.

Cheok, G., \& Lew, H. S. (1991). Performance of precast concrete beam to column connections subject to cyclic loading. $\mathrm{PCl}$ Journal, 56-67.

Im, H., Park, H., \& Eom, T. (2013). Cyclic loading test for reinforced-concrete-emulated beam-column connection of precast concrete moment frame. ACl Structural Journal, (110).

Kusuhara, F., Asukawa, K., Shiohara, H., \& Otani, S. (2004). Test of reinforced concrete interior beam-column joint subassemmblage with eccentric beams. 13th World Conference on Earthquake Engineering. Vancouver, B.C., Canada.

Maspons, R. (1987). Prefabricación . La Habana, Cuba: Editorial ISPJAE.

Negro, P., \& Toniolo, G. (2012). Design guidelines for connections of precast structures under seismic actions. Joint Research Centre of the European Commission. doi:10.2777/37605

Paredes, R., Ruiz, L., \& Tosca, J. (1988). Estudio de la junta viga-columna del sistema SMAC. La Habana: Centro Tecnico para el Desarrollo de los Materiales de Construccion (CTDMC).

Shariatmadar, H., \& Zamani, E. (2011). Experimental investigation of precast concrete beam to column connections subjected to reversed cyclic loads . 6th International Conference on Seismology and Earthquake Engineering.

Tosca, J., \& Ruiz, L. (1989). Instrucciones para la utilización del sistema constructivo SMAC. La Habana, Cuba: Empresa de Proyecto No.2. Ministerio de la Construcción. 